\title{
The Level of Malnutrition and Eating Attitude Among Addis Ababa University Students, Ethiopia, A Cross Sectional Study
}

\author{
Tefera Tezera Negera ${ }^{1}$, Jemal Haidar Ali ${ }^{2}$, Agajie Likie Bogale ${ }^{3}$ \\ ${ }^{1}$ Addis Ababa Institute of Technology, Addis Ababa University, Addis Ababa, Ethiopia \\ ${ }^{2}$ Department of Reproductive Health and Health Service Management, School of Public Health, College of Health Sciences, Addis Ababa \\ University, Addis Ababa, Ethiopia \\ ${ }^{3}$ Ethiopian Public Health Institute, Addis Ababa, Ethiopia
}

Email address:

tefera_tezera@yahoo.com (T. T. Negera),hjemal@gmail.com (J. H. Ali), agalb.2000@yahoo.com (A. L. Bogale)

\section{To cite this article:}

Tefera Tezera Negera, Jemal Haidar Ali, Agajie Likie Bogale. The Level of Malnutrition and Eating Attitude Among Addis Ababa University Students, Ethiopia, A Cross Sectional Study. Science Journal of Public Health. Vol. 4, No. 5, 2016, pp. 401-407.

doi: $10.11648 /$ j.sjph.20160405.16

Received: July 2, 2016; Accepted: July 30, 2016; Published: August 25, 2016

\begin{abstract}
This study examined the magnitude of malnutrition and eating attitude among 774 senior Addis Ababa university students proportionally selected and assessed for various socio demographic and anthropometric (BMI) statuses.The strength of the association between BMI status and independent variables was identified using odds ratio in the binary logistic regression. In addition the mean eating attitude captured through Likert scales and their weighted average were used to categorize the nutritional status level of the students. The burden of malnutrition was higher among campus residents, males, age group 18-27years, year two and three, from technology faculty, income below 500 ETB, educated family and café users. The highest eating attitude score is observed in the item "I like to eat (3.19). None of the covariates had significant association with malnutrition. To improve the university environment and produce productive graduates, the prevailing nutritional problem including some of the barriers though not significantly deserves the attention of the university including the ministry of education as the problem cannot be tackled by an isolated vertical approach.
\end{abstract}

Keywords: Magnitude, Malnutrition, Attitudes, University Students, Addis Ababa, Ethiopia

\section{Introduction}

Malnutrition is the direct consequence of inadequate dietary intake, the presence of disease, or their interaction in most cases [1]. Despite appreciable worldwide nutrition specific intervention, about 780 million people in developing countries still have no access to adequate food to meet their nutritional requirements [2] with highest case of under-nutrition malnutrition in South Asia.

Various studies including Ethiopia have indicated that nutritional problems shared similar factors in terms of their etiology [3-9]. These factors are interrelated and could span throughout the life cycle if timely intervention is not in place and demands for proper planning and effective preventative intervention program. The problem could go beyond children and have an effect on in-school adolescents joining tertiary schools like universities. According to Tefera et al, the transition from secondary schooling to university enrollment usually coerces students to adapt to a new environment is challenging to most of the students [10]. The new environment would definitely entail students to increased responsibility for their meal preparation and consumption of unhealthy dieting ranging from high intake of fast food, skipping meal, insufficient physical activity, low intake of fruits and vegetables further expose them to different forms of malnutrition which is interfering with the role of nutrition to propel sustainable development[11-14]. While most nutrition interventions are delivered through the health sector, non-health interventions like school community are also critical indicating the need for a multisectoral approach. For instance, eating behavior next to physical activity and 
sedentary behavior are among other important factor influencing the nutritional status of the students [15] in addition to the rapid changes in physical growth and psychosocial development which have placed students as nutritionally vulnerable groups [16-18]. As a result, many University students may end up in developing underweight, overweight or obese.

The selection of unhealthy food and high cost of healthy foods may have also a negative impact on university student's eating attitude needs the attention of the university management [19]. Nonetheless, such evidences in the Ethiopian university context are either limited or nil particularly in the proposed study sites. Against this background information, the present study examined the magnitude of the malnutrition among university students and uncovers the predictors for evidence based intervention and allow the current and future generation of students to be free from abnormal nutrition and improved academic performance since the government of Ethiopia is committed to bring upfront the value of nutrition as its development agenda.

\section{Study Setting and Design}

A cross-sectional (university based) study with analytic component was conducted from June, 2014-July 2015 in three conveniently selected campuses out of the eight campuses of Addis Ababa University (AAU). The three campuses namely Technology $(7,239=35.9 \%)$, Natural Sciences $(1,432=7.1 \%)$ and social sciences $(2,933=14.5)$ were selected because of their large number of student representations, logistical reasons and availability of clinics. According to the 2014 AAU report, 20,120 undergraduate students were registered in the 2014/15 academic calendar and displayed in Table 1 [20].

Table 1. College Profiles of Addis Ababa University and availability of polyclinic, 2015.

\begin{tabular}{lllll}
\hline Name of campuses/colleges & Campus site & Enrolled student number & Doctors available & Has clinics and full timer nurses \\
\hline Social Science & AA & 2933 & Yes Part-timer & Yes \\
AA Institute of Technology & AA & 7239 & Yes Part-timer & Yes \\
Natural Science & AA & 1432 & no & Yes \\
EI Building Construction & AA & 2033 & no & Yes \\
Health Sciences & AA & 2900 & no & Yes \\
Veterinary Medicine & DebreZeit & 450 & no & Yes \\
College of Commerce & AA & 2483 & no & Yes \\
Agriculture & Fiche & 650 & 2 part-time doctors \\
Overall & 8 campuses & 20,120 students & & All had nurses \\
\hline
\end{tabular}

$\mathrm{AA}=$ Addis Ababa; EI=Ethiopian Institute

A multi-stage sampling method was employed to select the students. In the selected campuses, cumulative populations were calculated, and the attributed number was assigned. The sampling interval was then calculated by dividing the total number of the students with the estimated sample size. A random number was drawn using a random number table and the first participant was selected based on this number and added the sampling interval sequentially until the required sample size was reached. All potential candidates were invited and those who agreed to participate were included.

\subsection{Ethical Considerations}

Ethics approval was obtained from the school of Public Health Ethics Committee of Addis Ababa University College of Health Sciences. All participants who consented to the study were informed of their rights to refuse participation or withdraw from the study without having to give reasons. Participants were guaranteed anonymity and all information provided would be treated with confidentiality. Those students who were under or overweight were also counseled after the end of the study.

\subsection{Sample Size Determination}

The required sample size was estimated using a $35.6 \%$ prevalence of underweight [21] with $5 \%$ of the marginal error and $95 \%$ confidence level with design effect of 2 . Thus, overall calculated sample size is 774 . The estimated sample size was then allocated proportionally across the three campuses namely social sciences/main campus $(n=196)$, technology $(\mathrm{n}=482)$ and natural sciences $(\mathrm{n}=96)$.

\subsection{Data Collection Process}

Data were collected using a pre-tested structured questionnaire prepared in the local language Amharic designed by reviewing pertinent research findings on the issue under caption. The important variables included in the questionnaire were socio-demographic, eating attitude containing 36 items and displayed in Table 3, weight and height measurements. Three data collectors/enumerators fluent in the local languages and two supervisors (one Health Officer and one Nurse) with relevant experience were recruited and trained for two days on the method of the data collection. The training addressed issues such as the content of the questionnaire, basic interviewing skills, and filling out of the questionnaire, weight and height measurements. The 36 items referring to eating attitude adopted from Nigerian study [22] and were measured using a 4-point Likert scale ranging from rarely $/$ never $=1$; sometimes $=2$; often $=3$ and always $=4$ for all the items and were collected based on participants' self-reported answers in response to the specific questions. All the respondents were interviewed on a one-to-one basis by the enumerators under close observation of the investigators. The interviews lasted for 25-30 minutes and were conducted during their non-class hours. 


\subsection{Anthropometric Measurements}

A digital bathroom scale was used to obtain weight. Prior to each weighing, the scale was adjusted to zero reading to enhance validity. Each participant was weighed twice to improve the accuracy and reliability of measurement; the mean value to the nearest $0.1 \mathrm{~kg}$, as recommended by the World Health Organization was recorded. A standardized measuring board with a fixed head rest and a moveable foot piece was used to determine height. Height was measured without shoes following standard procedures with the head in upright position and the body firmly stretched and resting on the board to the nearest $0.1 \mathrm{~cm}$.

\subsection{Data Quality Management}

The quality was observed at different levels and included the followings: due emphasis was given to questionnaire designing to capture the objectives of the study, logically sequenced, free of scientific terms and non-leading structured questionnaire and pre-tested before data collection. The data collecting team was trained on the study protocol thoroughly including how to maintain confidentiality / privacy of the participants. The collected data were checked by the investigating team on daily basis for any incompleteness and / or consistency and timely action was made.

\subsection{Statistical Analysis}

Data were edited manually initially, and then entered and organized using Epi Info version 3.5.3 and exported to SPSS version 20 for descriptive and inferential analyses. Weight and height of the students were converted to body mass index $\left(\mathrm{BMI}=\mathrm{Kg} / \mathrm{m}^{2}\right.$ ) as recommended by the World Health Organization and to determine the malnutrition level and were classified as normal where BMI value falls between 18.5 and $24.9 \mathrm{Kg} / \mathrm{m}^{2}$ and any value outside these ranges as abnormal. To ascertain the association between the dependent variables and the explanatory variables, all socio-demographic characteristics and other covariates associated in bivariate with $\mathrm{p}<0.2$ were used and entered using stepwise logistic regression with odds ratios (AORs) and confidence intervals $(95 \% \mathrm{CI})$ and a $P<0.05$ was considered statistically significant. The 36 items assessing the eating attitudes were evaluated and the means were compared with the level of malnutrition. The mean rating score for each item was calculated by multiplying the number of answers or responses in each category by its rating value (1 to 4 ), obtaining a sum and dividing by the total number of responses for that item; that is the level of malnutrition was calculated as frequency and rating value i.e. $($ fully apply $\times 4)+($ sometimes apply $\times 3)+($ rarely apply $\times 2)+$ (doesn't apply $\times 1$ ) divided by the total number of responses for the specific item to categorize the intake level as adequate and inadequate [23].

\section{Result}

A total of 757 University students participated in the study with $97.8 \%$ response rate. The majority $(81.1 \%)$ were campus residents with male preponderance $(72.7 \%)$. The vast majority $(99.6 \%)$ were in the age range of 18 to 27 with a mean age of $21.6 \pm 1.78$ years.

Most (30.1\%) of the participants were from year three and about one-third were from technology faculty. Over two-thirds (67.9\%) used University cafeteria. Among non-café users, $78(32.1 \%)$ prepare their food for themselves and the rest $165(67.9 \%)$ eat elsewhere. Regarding parental education, over half $(57.0 \%)$ had formal education and $426(56.3 \%)$ earned less than 500 ETB equivalent.

The aggregate of underweight and overweight (malnutrition) was higher among campus residents 243(40.0\%), males 209 (38.0\%), age group 18-27years 291 (38.6\%), year two and three $163(37.2 \%)$, from technology faculty $190(40.4 \%)$, income below 500 ETB 169(39.7\%), educated family (32.6\%), café users $(40.3 \%)$ as well as non-café users $(35.8 \%)$. Nonetheless, the proportion of overweight was higher among campus residents, males, age group 18-27years, year two and three, from technology faculty, income above 500 ETB, educated family and ate elsewhere. Similarly, the magnitude of underweight was also higher among campus residents, males, age group 18-27 years, year two and three, from technology faculty, income below 500 ETB, educated family and café users. Those students consuming their meals elsewhere had higher proportion of both underweight and overweight (Table 2) indicating double burden of malnutrition.

Of the 757 enrolled students, who experienced both under and overweight were further checked against their eating attitudes. Based on the 36 items of eating attitudes, 24 items were above and the rest 12 were below the mean score. The low items motioned by the malnourished students ranged from taking vitamin drinks (1.68) and nutritional supplements (1.7); eating when in a bad mood (1.73); desire to buy and try out new food products as soon as they are released (1.7); do not care what to eat as long as it fills the tummy (1.7); eat precooked food, instant and frozen products, and delivery foods like pizza (1.8); abstain eating (1.8); highly valued precooked dishes in the supermarket (1.8); want to lose weight just by eating a well- balanced diet (1.8); buy natural foods and organic vegetables even if they cost more (1.9); dislike cooking and cleaning up afterwards (1.9) and want to save money on food and spend it on other things (1.9)" (Table 3).

Interestingly, although the burden of malnutrition was higher among campus residents 243(83.2\%), males 209 (71.6\%), age group 18-27years 291 (99.7\%), year two and three $163(55.8 \%)$, from technology faculty $190(65.1 \%)$, income below 500 ETB 169(57.9\%), educated family (33.6\%) and café users $(70.9 \%)$, the differences noted however were not significant in the binary logistic regression (Table 4). 
Table 2. Socio-demographic and other related characteristics of Addis Ababa University students by BMI status, Ethiopia, 2015 ( $n=757)$.

\begin{tabular}{|c|c|c|c|c|}
\hline \multirow[b]{2}{*}{ Variables } & \multirow[b]{2}{*}{$\begin{array}{l}\text { Characteristics frequency } \\
\text { with percentage }\end{array}$} & \multicolumn{3}{|l|}{ BMI status in $\mathrm{kg} / \mathrm{m}^{2}$} \\
\hline & & $\begin{array}{l}\text { 18.5-24.9 (normal) } \\
\text { Freq }(\%)\end{array}$ & $\begin{array}{l}<18.5 \text { (underweight) } \\
\text { Freq }(\%)\end{array}$ & $\begin{array}{l}>25 \text { (overweight/obese) } \\
\text { Freq }(\%)\end{array}$ \\
\hline \multicolumn{5}{|l|}{ Campus residents } \\
\hline Yes & $614(81.1)$ & $371(79.8)$ & $222(85.4)$ & $21(65.6)$ \\
\hline No & $143(18.9)$ & $94(20.2)$ & $38(14.6)$ & $11(34.4)$ \\
\hline \multicolumn{5}{|l|}{ Sex } \\
\hline Male & $550(72.7)$ & $341(73.3)$ & 189(72.7) & $20(62.5)$ \\
\hline Female & $207(27.3)$ & $124(26.7)$ & $71(27.3)$ & $12(37.5)$ \\
\hline \multicolumn{5}{|l|}{ Age } \\
\hline $18-27$ & 754(99.6) & $463(99.6)$ & $260(100)$ & $31(96.9)$ \\
\hline $28-37$ & $3(0.4)$ & $2(0.4)$ & 0 & $1(3.1)$ \\
\hline Mean & $21.6 \pm 1.78$ & & & \\
\hline \multicolumn{5}{|l|}{ Year of training } \\
\hline II-year & $208(27.5)$ & $126(27.2)$ & $71(27.4)$ & $11(34.4)$ \\
\hline III-year & $228(30.1)$ & $147(31.6)$ & $69(26.5)$ & $12(37.5)$ \\
\hline IV-year & $162(21.4)$ & $96(20.6)$ & $62(23.8)$ & $4(12.5)$ \\
\hline V-year & $159(21.0)$ & $96(20.6)$ & $58(22.3)$ & $5(15.6)$ \\
\hline Mean & $2.4 \pm 1.1$ & & & \\
\hline \multicolumn{5}{|l|}{ Field of study } \\
\hline Technology & $471(62.2)$ & 281(60.4) & $172(66.2)$ & $18(56.2)$ \\
\hline Social science & 192(25.4) & $123(26.5)$ & $59(22.7)$ & $10(31.3)$ \\
\hline Natural Science & $94(12.4)$ & $61(13.1)$ & $29(11.1)$ & $4(12.5)$ \\
\hline \multicolumn{5}{|l|}{ Income } \\
\hline$<500$ & $426(56.3)$ & $257(55.3)$ & $157(60.4)$ & $12(37.5)$ \\
\hline$\geq 500 \mathrm{ETB}$ & $331(43.7)$ & $208(44.7)$ & 103(39.6) & $20(62.5)$ \\
\hline \multicolumn{5}{|c|}{ Parental had formal education } \\
\hline No & $325(43.0)$ & $174(37.4)$ & $94(36.2)$ & $4(12.6)$ \\
\hline Yes & $432(57.0)$ & $291(62.6)$ & $166(63.8)$ & $28(87.4)$ \\
\hline \multicolumn{5}{|c|}{ Used campus cafeteria } \\
\hline Yes & $514(67.9)$ & $307(66.0)$ & 193(74.2) & $14(43.8)$ \\
\hline No & $243(32.1)$ & $158(34.0)$ & $67(25.8)$ & $18(56.2)$ \\
\hline \multicolumn{5}{|c|}{ Non-cafeteria eating place } \\
\hline Prepare themselves & $78(32.1)$ & $52(32.9)$ & $18(26.9)$ & $8(44.4)$ \\
\hline Eat elsewhere & $165(67.9)$ & $106(67.1)$ & $49(73.1)$ & $10(55.6)$ \\
\hline
\end{tabular}

$\mathrm{ETB}=$ Ethiopian Birr and 1 USD is equivalent to $22 \mathrm{ETB}$

Table 3. The burden of underweight and overweight of student and their eating attitudes, Addis Ababa University, Ethiopia ( $n=292$ ).

\begin{tabular}{|c|c|c|c|c|c|c|}
\hline Items & $\begin{array}{l}\text { Mostly doesn't } \\
\text { apply Freq (\%) }\end{array}$ & $\begin{array}{l}\text { Rarely apply } \\
\text { Freq (\%) }\end{array}$ & $\begin{array}{l}\text { Sometime } \\
\text { Freq }(\%)\end{array}$ & $\begin{array}{l}\text { Fully apply } \\
\text { Freq }(\%)\end{array}$ & Mean rate & $\begin{array}{l}\text { Percentof } \\
\text { each item }\end{array}$ \\
\hline 1. I try to eat a well -balanced diet. & $83(28.4)$ & $95(32.5)$ & $96(32.9)$ & $18(6.2)$ & 2.2 & 55.0 \\
\hline 2. I seriously would like to learn cooking. & $93(31.8)$ & $60(20.5)$ & $76(26.0)$ & $63(21.6)$ & 2.4 & 59.3 \\
\hline $\begin{array}{l}\text { 3. I check for food additive, food coloring, etc in } \\
\text { my food. }\end{array}$ & $114(39.0)$ & $90(30.8)$ & $63(21.6)$ & $25(8.6)$ & 2.0 & 49.9 \\
\hline $\begin{array}{l}\text { 4. I eat precooked food, instant and frozen } \\
\text { products, and delivery foods. }\end{array}$ & $133(45.5)$ & $93(31.8)$ & $51(17.5)$ & $15(5.1)$ & 1.82 & 45.5 \\
\hline $\begin{array}{l}\text { 5. I take nutritional supplements like vitamin } \\
\text { tablets or similar products. }\end{array}$ & $153(52.4)$ & $77(26.4)$ & $50(17.1)$ & $12(4.1)$ & 1.73 & 43.2 \\
\hline $\begin{array}{l}\text { 6. The amount of my food intake varies depending } \\
\text { on my mood. }\end{array}$ & $53(18.2)$ & $72(24.7)$ & $79(27.1)$ & $88(30.1)$ & 2.69 & 67.3 \\
\hline $\begin{array}{l}\text { 7. Practicing healthy eating behavior is important } \\
\text { to me. }\end{array}$ & $35(12.0)$ & $43(14.7)$ & $82(28.1)$ & $132(45.2)$ & 3.1 & 76.6 \\
\hline 8. I would like people to commend my cooking. & $97(33.2)$ & $77(26.4)$ & $77(26.4)$ & $41(14.0)$ & 2.2 & 55.3 \\
\hline $\begin{array}{l}\text { 9. I buy natural foods and organic vegetables even } \\
\text { if they cost more. }\end{array}$ & $124(42.5)$ & $90(30.8)$ & $54(18.5)$ & $24(8.2)$ & 1.9 & 48.1 \\
\hline 10. I try not to eat too much. & $67(22.9)$ & $54(18.5)$ & $75(25.7)$ & $96(32.9)$ & 2.68 & 67.1 \\
\hline 11. Fast food is delicious and convenient. & $54(18.5)$ & $54(18.5)$ & $88(30.1)$ & $96(32.9)$ & 2.77 & 69.3 \\
\hline $\begin{array}{l}\text { 12. I highly value precooked dishes in the } \\
\text { supermarket. }\end{array}$ & $139(47.6)$ & $81(27.7)$ & $54(18.5)$ & $18(6.2)$ & 1.83 & 45.8 \\
\hline 13. I try to eat slowly and chew well. & $53(18.2)$ & $63(21.6)$ & $73(25.0)$ & $103(35.3)$ & 2.77 & 69.3 \\
\hline $\begin{array}{l}\text { 14. I like to change the dishes I use depending on } \\
\text { my mood. }\end{array}$ & $100(34.2)$ & $70(24.0)$ & $77(26.4)$ & $45(15.4)$ & 2.23 & 55.7 \\
\hline 15. I feel uneasy about trusting important foods. & $98(33.6)$ & $81(27.7)$ & $80(27.4)$ & $33(11.3)$ & 2.16 & 54.1 \\
\hline 16. I want to save money on food and spend it on & $119(40.8)$ & $81(27.7)$ & $69(23.6)$ & $23(7.9)$ & 1.98 & 49.7 \\
\hline
\end{tabular}




\begin{tabular}{|c|c|c|c|c|c|c|}
\hline Items & $\begin{array}{l}\text { Mostly doesn't } \\
\text { apply Freq (\%) }\end{array}$ & $\begin{array}{l}\text { Rarely apply } \\
\text { Freq (\%) }\end{array}$ & $\begin{array}{l}\text { Sometime } \\
\text { Freq }(\%)\end{array}$ & $\begin{array}{l}\text { Fully apply } \\
\text { Freq }(\%)\end{array}$ & Mean rate & $\begin{array}{l}\text { Percentof } \\
\text { each item }\end{array}$ \\
\hline \multicolumn{7}{|l|}{ other things. } \\
\hline 17. I try to eat a variety of foods. & 64(21.9) & $78(26.7)$ & $108(37.0)$ & $42(14.4)$ & 2.44 & 60.96 \\
\hline 18. I try to eat at the same time every day. & $77(26.4)$ & $73(25.0)$ & $89(30.5)$ & $53(18.2)$ & 2.40 & 60.1 \\
\hline 19. I try to enjoy eating my meals. & $41(14.0)$ & $60(20.5)$ & $116(39.7)$ & $75(25.7)$ & 2.77 & 69.3 \\
\hline $\begin{array}{l}\text { 20. I think there are many tasty instant noodle } \\
\text { soups. }\end{array}$ & 104(35.6) & $89(30.5)$ & $63(21.6)$ & $36(12.3)$ & 2.11 & 52.7 \\
\hline $\begin{array}{l}\text { 21. I would like to know more about food } \\
\text { nutrients and what functions they have. }\end{array}$ & $47(16.1)$ & $50(17.1)$ & $86(29.5)$ & $109(37.3)$ & 2.88 & 72.0 \\
\hline $\begin{array}{l}\text { 22. I do not care what I eat as long as it fills my } \\
\text { stomach. }\end{array}$ & $145(49.7)$ & $75(25.7)$ & $54(18.5)$ & $18(6.2)$ & 1.81 & 45.3 \\
\hline $\begin{array}{l}\text { 23. I want to buy and try out new food products as } \\
\text { soon as they are released. }\end{array}$ & $149(51.0)$ & $71(24.3)$ & $58(19.9)$ & $14(4.8)$ & 1.78 & 44.6 \\
\hline $\begin{array}{l}\text { 24. I want to lose weight just by eating a well- } \\
\text { balanced diet. }\end{array}$ & $166(56.8)$ & $47(16.1)$ & $42(14.4)$ & $37(12.7)$ & 1.83 & 45.7 \\
\hline 25. I always drink vitamins drinks. & $162(55.5)$ & $73(25.0)$ & $44(15.1)$ & $13(4.5)$ & 1.68 & 42.1 \\
\hline 26. I don't mind eating the same things every day. & $92(31.5)$ & $74(25.3)$ & $78(26.7)$ & $48(16.4)$ & 2.28 & 57.0 \\
\hline 27. I only want to eat my favorite dishes. & $54(18.5)$ & $76(26.0)$ & $103(35.3)$ & $59(20.2)$ & 2.57 & 64.3 \\
\hline 28. I dislike cooking and cleaning up afterwards. & $141(48.3)$ & $66(22.6)$ & $57(19.5)$ & $28(9.6)$ & 1.9 & 47.6 \\
\hline 29. When food taste good, I eat more than usual. & $41(14.0)$ & $46(15.8)$ & $94(32.2)$ & $111(38.0)$ & 2.94 & 73.5 \\
\hline 30. I worry about calories when eating. & $129(44.2)$ & $65(22.3)$ & $58(19.9)$ & $40(13.7)$ & 2.03 & 50.8 \\
\hline 31. My eating habits are normal. & $61(20.9)$ & $57(19.5)$ & $100(34.2)$ & $74(25.3)$ & 2.64 & 66.0 \\
\hline 32. It's OK not to eat. & $152(52.1)$ & $65(22.3)$ & $52(17.8)$ & $23(7.9)$ & 1.82 & 45.4 \\
\hline 33. I like to eat. & 29(9.9) & $33(11.3)$ & $83(28.4)$ & $147(50.3)$ & 3.19 & 79.8 \\
\hline 34. I feel like eating when I am in a bad mood. & $165(56.5)$ & $63(21.6)$ & $41(14.0)$ & $23(7.9)$ & 1.73 & 43.3 \\
\hline $\begin{array}{l}\text { 35. When I see a person eating, I want to eat as } \\
\text { well. }\end{array}$ & $91(31.2)$ & $80(27.4)$ & $80(27.4)$ & $41(14.0)$ & 2.24 & 56.0 \\
\hline $\begin{array}{l}\text { 36. I like to strengthen relationships with other by } \\
\text { eating together. }\end{array}$ & 64(21.9) & $42(14.4)$ & $96(32.9)$ & $90(30.8)$ & 2.73 & 68.2 \\
\hline
\end{tabular}

*mostly doesn't apply score $=1$, rarely apply $=2$, sometimes $=3$, fully apply $=4$.

Table 4. Factors associated with burden of underweight and overweight of students, Addis Ababa University, Ethiopia, 2015. (n=292).

\begin{tabular}{|c|c|c|c|c|}
\hline \multirow{2}{*}{$\begin{array}{l}\text { Characteristics } \\
\text { Campus residents }\end{array}$} & \multicolumn{2}{|c|}{ Malnourished } & \multirow[t]{2}{*}{ COR $(95 \% \mathrm{CI})$} & \multirow[t]{2}{*}{ AOR (95\%CI) } \\
\hline & $\mathrm{N}$ & $\%$ & & \\
\hline Yes & 243 & 83.2 & 1 & 1 \\
\hline No & 49 & 16.8 & $1.26(0.86-1.84)$ & $0.99(0.55-1.79)$ \\
\hline \multicolumn{5}{|l|}{ Sex } \\
\hline Male & 209 & 71.6 & 1 & 1 \\
\hline Female & 83 & 28.4 & $0.92(0.66-1.27)$ & $0.76(0.51-1.14)$ \\
\hline \multicolumn{5}{|l|}{ Age group } \\
\hline $18-27$ & 291 & 99.7 & 1 & 1 \\
\hline $28-37$ & 1 & 0.3 & $1.26(0.11-13.9)$ & $1.25(0.11-14.23)$ \\
\hline \multicolumn{5}{|l|}{ Year of training } \\
\hline II-year & 82 & 28.1 & 1 & 1 \\
\hline III-year & 81 & 27.7 & $1.18(0.8-1.74)$ & $1.28(0.84-1.93)$ \\
\hline IV-year & 66 & 22.6 & $0.95(0.62-1.44)$ & $1.02(0.65-1.60)$ \\
\hline V-year & 63 & 21.6 & $0.99(0.65-1.51)$ & $1.09(0.68-1.77)$ \\
\hline \multicolumn{5}{|l|}{ Field of study } \\
\hline Technology & 190 & 65.1 & 1 & 1 \\
\hline Social science & 69 & 23.6 & $1.21(0.85-1.71)$ & $1.61(0.77-3.37)$ \\
\hline Natural science & 33 & 11.3 & $1.25(0.79-1.98)$ & $1.35(0.46-3.94)$ \\
\hline \multicolumn{5}{|l|}{ Cafeteria user } \\
\hline Yes & 207 & 70.9 & 1 & 1 \\
\hline No & 85 & 29.1 & $1.25(0.91-1.72)$ & $1.53(0.90-2.60)$ \\
\hline \multicolumn{5}{|c|}{ Education of parents } \\
\hline No & 98 & 33.6 & 1 & 1 \\
\hline Yes & 194 & 66.4 & $0.85(0.63-1.14)$ & $0.76(0.55-1.06)$ \\
\hline \multicolumn{5}{|c|}{ Monthly Income for students } \\
\hline$<500$ Birr & 169 & 57.9 & 1 & 1 \\
\hline$\geq 500$ Birr & 123 & 42.1 & $1.11(0.83-1.49)$ & $1.10(0.79-1.52)$ \\
\hline
\end{tabular}




\section{Discussion}

In order to deal with all nutrition related consequences the first crucial step is to assess the nutritional status of individuals using anthropometric, biochemical, clinical, and dietary methods in combination or alone. Some of the aforementioned methods are expensive and require skilled personnel though sensitive whereas anthropometric is easy, non-invasive and very informative method that can give gradable information in determining the nutritional status in terms of body composition and body size [24].

Malnutrition is the result of inadequate nutrient intake and illnesses including changes in diet and lifestyles such as smoking, lack of exercise, and risky alcohol consumptions [3, 25 ] in addition to the rapid changes in physical growth and psychosocial development. Many University students experience such behavior and undergo into developing malnutrition [10] which this study has also substantiated.

Malnutrition in this study was slightly higher than (38.6\%) the Lebanese study findings $(35.3 \%)$ with males being more affected $(62.5 \%)$ in this study than the Lebanese university students $(50.0 \%)$. This difference is attributed to sample size difference and the study settings [26]. On the other hand, our finding is concordant with the study conducted in Thailand [27]. According to this study, malnutrition in the form of underweight and overweight was nearly seen in less than half of the students residing in the campus with males being affected more than females. In addition younger age groups between 18-27years were the most affected. Most of the malnourished students were from year two and three, technology faculty indicating students from these campuses who are younger need the most attention.

Similarly, one in two students from households earning below $500 \mathrm{ETB}$, one in three in educated family, two in three in café users as well as one in three among non-café users had malnutrition. When the level of malnutrition is disaggregated into underweight and overweight, most of the students experienced the problem were seen among campus residents, males, younger age, year two and three, from technology faculty, income below 500 ETB and educated family. On the other hand, underweight was higher among café users (74.2 percent) and overweight in non café users (56.2 percent). Interestingly, those students consuming their meals elsewhere had higher proportion of both underweight and overweight suggesting the existence of double burden of malnutrtion.

The distribution of the sampled students eating attitude and behavior was also described in relation to malnutrition. Based on the 36 items of eating attitudes, 12 items were found below the mean score among malnourished students. Most of the items were taking vitamin drinks and nutritional supplements including eating when in a bad mood. Others were desire to buy and try out new food products as soon as they are released, no preferences of eating as long as the food fills their tummy; eating precooked food, fast food; abstain eating which appears to contribute to their abnormal nutrition. This finding is consistent with other studies in
Chinese university students [28].

Although the burden of malnutrition was higher among campus residents, males, age group 18-27 years, year two and three, from technology faculty, income below 500 ETB, educated family and café users, the differences noted however were not significant in the binary logistic regression.

\section{Strength and Limitation}

There has been no study which availed timely information on the magnitude of malnutrition among the students and considered an input for the University officials. Some of the limitations of the study however, were social desirability bias from respondents due to the nature of the study and could be affected by seasonally and we cannot establish cause and effect relationship though maximum effort was conducted to decrease the effect of these limitations on the validity of the finding during the time of pre survey and data collection period.

\section{Conclusion}

The burden of malnutrition in the form of underweight and overweight are prevalent among campus residents with males being more affected. Twelve items were below the mean score among malnourished students and included taking vitamin drinks and nutritional supplements including eating when in a bad mood. It is essential to improve the nutrition situation in the university since universities are the final opportunities for producing productive citizens.

\section{Authors' Contribution}

TT designs the study and collected the data. JAH contributed in the interpretation of the data and manuscript write up. AL participated in the data analysis and manuscript write up. All authors read, critically revised and approved the final manuscript.

\section{Acknowledgement}

Addis Ababa University, School of public health is acknowledged for clearing the study. And also Addis Ababa Institute of Technology, Addis Ababa University for financial support. Heartfelt appreciation goes to the senior author Dr. Jemal Haidar for the overall contribution to the study. Finally, data collectors and study participants for their concern in the study.

\section{References}

[1] World Health Organization (WHO). The Use and Interpretation of Anthropometry, Geneva, Switzerland; 1995.

[2] Latham MC. Human Nutrition. In: The Developing World. Food and Nutrition Series, Food and Agriculture Organization, 1997; 29. 
[3] Kikafunda JK, Walker AF, Collet D, James FT. Risk factors for early childhood malnutrition in Uganda. Paediatrics 1998; 102 (4): 45 .

[4] Griffiths P, Madise N, Whitworth A, Matthews Z. A tale of two continents: a multilevel comparison of the determinants of child nutritional status from selected African and Indian regions. Health \& Place 2004; 10:183-199.

[5] Heaton TB, Forste R. Rural/urban differences in child growth and survival in Bolivia. Rural Sociology 2003; 68 (3): 410.

[6] Zamaliah MM, Mohd Nasir MT, Khor GL, Tee ES. Socio-economic determinants of nutritional status of children in rural peninsular Malaysia. Asia Pac J Clin Nutr 1998; 7 (3/4): 307-310.

[7] NoorHayati MI, Mohammod CG, Oothuman P, Azizi O, Fatimah A, Fatimah MS. Malnutrition and its risk factors among children 1-7 years old in rural Malaysian communities. Asia Pac J Clin Nutri 1997; 6 (4):260-264.

[8] Chee HL, Khor GL, Fatimah A, Wan Abdul Manan WM, Mohd Nasir MT, Nik Shanita S et al. Nutritional assessment of pre-school children in rural villages for the family dynamics, lifestyles and nutrition study; Prevalence of under nutrition and relationship to household socioeconomic indicators. Mal J Nutr 2002; 8 (1):33-53.

[9] Haidar J, G. Abate, Kogi. M, S. Pernille. Risk Factors for child under-nutrition with a human rights edge in rural villages of North Wollo, Ethiopia. East Afri Med J 2005; 82 (12): 625-30.

[10] Negera TT, Ali JH. Eating Behavior and Body Mass Index Status of Senior Regular Undergraduate Students of Addis Ababa University. Science Journal of Public Health 2016; 4 (2): 107-116.

[11] Walid E, Christiana S, Rafael T. Relationships between food consumption and living arrangements among university students in four European countries-A cross -sectional study. Nutrition journal 2012; 11:1-7.

[12] Nelson MC, Story M, Larson NI, Neumark-Sztainer D, Lytle L A. Emerging adulthood and college-aged youth: an overlooked age for weight-related behavior change. Obesity 2008; 16 : 2205-2211.

[13] Savige GS, Ball K, WorsleyA, Crawford D. Food intake patterns amongAustralianadolescents. Asia Pac J Clin Nutr 2007; 16:738-747.

[14] Shi Z, Lien N, Kumar BN and Holmboe-Ottesen G: Socio-demographicdifferences in food habits patterns of school children and adolescents in and preferences of school adolescents in Jiangsu Province, China. Eur J Clin Nutr 2005, 59:1439-1448.

[15] Tom D, Peter C, Ilse D and Benedicte D. Determinants of Eating Behavior in University Students: A qualitative study using focus group discussions. BMC Public Health, 2014; $14: 53$.
[16] Lua P, Wan D, Wan P, Sharhri L. Nutrition quality of life among female- majority Malay undergraduate students of Health Sciences. 2012; 1:1-7.

[17] Miso K and HongmieL. Overestimation of own body Weights in Female University Students: Associations with Life Styles, Weight control behaviors and depression. Nutrition Research and Practice, 2010; 4 (6): 499-506.

[18] LaCaille LJ, Dauner KN, Krambeer RJ, Pedersen J. Psychosocial and environmental determinants of eating behaviors, physical activity and weight change among college students: a qualitative analysis. Journal of American College Health 2011; 59 (6): 531-538.

[19] Gan W, Nasir M, Zalilah M and Haziza A. Difference in eating behaviors, dietary intake and body weight status between male and female Malaysian university students 2011;17:213-228.

[20] Addis Ababa University, Dean of Student Office summer of students registeredfor academic calendar of 2014; 1: 1-10.

[21] Takele T and Henock A. Hypertension and Associated factors among University Students in Gondar, Ethiopia: across sectional study. BMC Public Health 2014; 14: 1-5.

[22] Nmor J, Nwaka KH and Nmor JC. Does eating behaviors among university students in Nigeria differ based on body mass index differences? Science Journal of Public Health 2014; 2 (1): 38-46.

[23] Bogale AL, Kassa HB, Ali JH. Patients perception and satisfaction on quality of laboratory malaria diagnostic service in Amhara Regional State, Northwest Ethiopia, Malaria Journal (2015)14:241.

[24] Neyestani TR, Dad-khah M, Haidari H, Zowghi T, Maddah M, Nematy M, et al.Determination of the Actual Height Predictors in Iranian Healthy Children Archive of SID Patients and Methods, 2009; 1-6.

[25] Wu F, Guo Y, Chatterji S, Zheng Y, Naidoo N, Jiang Y, et al.Common risk factors for chronic non-communicable diseases among older adults in China, Ghana, Mexico, India, Russia and South Africa: the study on global AGEing and adult health (SAGE) wave 1, BMC Public Health 2015; 15:88.

[26] Yahia N, Achkar A, Abdallah A and Rizk S. Eating habits and obesity among Lebanese university students. Nutrition Journal 2008; 7 (32):1-6.

[27] Pengpid S, Peltzer K. Prevalence of overweight and underweight and its associated factors among male and female university students in Thailand, HOMO-Journal of Comparative Human Biology 2015; 66: 176-186.

[28] Sakmaki R, Toyama K, Amamoto R, Liu CJ, Shinfukun N. Nutritional knowledge, food habits and health attitude of Chinese university students across sectional study. Nutr J. 2005; 4 (4):1-5. 